\title{
Inhibitor of apoptosis protein expression in glioblastomas and their in vitro and in vivo targeting by SMAC mimetic GDC-0152
}

\author{
A Tchoghandjian ${ }^{1,4}$, A Soubéran ${ }^{1,4}$, E Tabouret $^{1,2}$, C Colin ${ }^{1}$, E Denicolail ${ }^{1}$, C Jiguet-Jiglaire ${ }^{1}$, A El-Battari ${ }^{1}$, C Villard ${ }^{1}$, N Baeza-Kallee ${ }^{1}$ \\ and D Figarella-Branger ${ }^{\star, 1,3}$
}

Glioblastomas (GBMs) are the most aggressive primary brain tumors in adult and remain a therapeutic challenge. Targeting key apoptosis regulators with the ultimate aim to restore apoptosis in tumor cells could be an interesting therapeutic strategy. The inhibitors of apoptosis proteins (IAPs) are regulators of cell death and represent attractive targets, especially because they can be antagonized by SMAC mimetics. In this study, we first investigated the expression of CIAP1, cIAP2, XIAP and ML-IAP in human GBM samples and in four different cell lines. We showed that all GBM samples and GBM cell lines expressed all these IAPs, although the expression of each IAP varied from one case to another. We then showed that high level of ML-IAP predicted worse progressionfree survival and overall survival in both univariate and multivariate analyses in two independent cohorts of 58 and 43 primary human GBMs. We then used GDC-0152, a SMAC mimetic that antagonizes these IAPs and confirmed that GDC-0152 treatment in vitro decreased IAPs in all the cell lines studied. It affected cell line viability and triggered apoptosis, although the effect was higher in U87MG and GL261 than in GBM6 and GBM9 cell lines. In vivo, GDC-0152 effect on U87MG orthotopic xenografts was dose dependent; it postponed tumor formation and slowed down tumor growth, significantly improving survival of GBM-bearing mice. This study revealed for the first time that ML-IAP protein expression correlates with GBM patient survival and that its antagonist GDC-0152 improves outcome in xenografted mouse.

Cell Death and Disease (2016) 7, e2325; doi:10.1038/cddis.2016.214; published online 4 August 2016

Glioblastomas (GBMs), the most common primary brain tumors in adult, remain a therapeutic challenge. Classified as grade IV by WHO, the aggressiveness of GBMs mainly resides in their highly invasive and proliferative behavior, and in their cellular and molecular heterogeneity. ${ }^{1}$ Despite the many clinical trials ongoing, few therapeutic improvements have been made in these past 10 years, with the median overall survival (OS) remaining at $\sim 15$ months. The standard of care is still currently unchanged since 2005 and consists of combining radiotherapy with concomitant and adjuvant temozolomide. ${ }^{2}$ Recently, a promising anti-angiogenic therapy (Bevacizumab) failed to improve OS in two independent phase III trials (AVAglio and RTOG 0825), supporting evidence that GBMs are refractory to treatments. ${ }^{3,4}$

Treatment resistance is a hallmark of cancer cells that develop strategies to bypass cell death. ${ }^{5}$ Inhibitor of apoptosis proteins (IAPs) are a well-conserved family of eight proteins including clAP1 (cellular inhibitor of apoptosis protein-1), cIAP2 (cellular inhibitor of apoptosis protein-2), XIAP (X-linked inhibitor of apoptosis protein) and ML-IAP (melanoma inhibitor of apoptosis protein), often expressed in many human cancers. ${ }^{6}$ IAPs are anti-apoptotic proteins contributing to treatment resistance by inhibiting caspase activation. Therefore, their expression in cancers is usually correlated with poor prognosis. ${ }^{7,8}$ IAPs are characterized by the presence of one to three Baculovirus IAP Repeat (BIR) domains, necessary for protein-protein interactions like caspase inhibitory interactions, typically arranged in the protein's amino terminus. clAP1, cIAP2, XIAP and ML-IAP also contain a carboxylterminus RING (Really Interesting New Gene) domain, working as an E3-ubiquitin ligase. ${ }^{9}$ Therefore, these IAPs have the capability of auto- or hetero-ubiquitination leading to proteasomal degradation. Thanks to their E3-ubiquitin ligase activity, the level of IAPs can be controlled by endogenous antagonists

\footnotetext{
${ }^{1}$ Aix-Marseille University, Inserm, CRO2 UMR_S 911, Marseille, France; ${ }^{2}$ AP-HM, Timone Hospital, Department of Neuro-Oncology, Marseille, France and ${ }^{3}$ AP-HM, Timone Hospital, Department of Anatomopathology, Marseille, France

*Corresponding author: D Figarella-Branger, Aix-Marseille University, Inserm, CRO2 UMR_S 911, 27 Boulevard Jean Moulin, Cedex 05, 13385 Marseille, France. Tel: +33 4 913244 43; Fax: +33 4912542 32; E-mail: dominique.figarella-branger@univ-amu.fr

${ }^{4}$ These authors contributed equally to this work.

Abbreviations: a.u., arbitrary unit; bFGF, basic fibroblast growth factor; BIR, baculovirus IAP repeat; BSA, bovine serum albumin; cIAP1/2, cellular inhibitor of apoptosis protein-1/2; cDNA, complementary DNA; DMEM, Dulbecco's modified Eagle's medium; DMSO, dimethyl sulfoxide; DTT, dithiothreitol; ECL, enhanced chemiluminescence; EGF, epidermal growth factor; EGFP, enhanced green fluorescent protein; FFPE, formalin-fixed, paraffin-embedded; GBM, glioblastoma; GFAP, glial fibrillary acidic protein; $\mathrm{HCl}$, hydrochloric acid; HR, hazard ratio; IAP, inhibitor of apoptosis protein; IgG, immunoglobulin G; iRFP, near-infrared fluorescent protein; ML-IAP, melanoma inhibitor of apoptosis protein; MTT, bromure de 3-(4,5-dimethylthiazol-2-yl)-2,5-diphenyl tetrazolium; NP-40, Nonidet P-40; OS, overall survival; PAGE, polyacrylamide gel electrophoresis; PBS, phosphate-buffered saline; PFS, progression-free survival; RING, real interesting new gene; ROC, receiver operating characteristic; r.p.m., revolutions per min; SDS, sodium dodecylsulfate; SRM, selected reaction monitoring; Smac, second mitochondria derived activator of caspases; TMA, tissue microarray; TRAIL-R2, necrosis-factor-related apoptosis-inducing ligand receptor 2; Tris, tris(hydroxymethyl)-aminomethane; UPLC, ultrahigh performance liquid chromatography; XIAP, X-linked inhibitor of apoptosis protein

Received 26.1.16; revised 25.5.16; accepted 20.6.16; Edited by G Ciliberto
} 
Table 1 Patient characteristics

\begin{tabular}{|c|c|c|c|c|}
\hline Characteristics & TMA $1, N=58$ & $\%$ & TMA 2, $N=43$ & $\%$ \\
\hline $\begin{array}{l}\text { Median age (range) } \\
K P S\end{array}$ & $61.7(20.5-81.9)$ & & $57(21.1-78.7)$ & \\
\hline $\begin{array}{l}K P S \\
\quad<70 \\
\geqslant 70\end{array}$ & $\begin{array}{l}14 / 58 \\
44 / 58\end{array}$ & $\begin{array}{l}24.14 \\
75.86\end{array}$ & $\begin{array}{l}\text { Unknown } \\
\text { Unknown }\end{array}$ & \\
\hline Type of surgery & & & & \\
\hline $\begin{array}{l}\text { Gross total resection } \\
\text { Other (partial excision, biopsy) }\end{array}$ & $\begin{array}{l}37 / 57 \\
20 / 57\end{array}$ & $\begin{array}{l}63.8 \\
36.2\end{array}$ & $\begin{array}{l}16 / 42 \\
26 / 42\end{array}$ & $\begin{array}{l}61.9 \\
38.1\end{array}$ \\
\hline $\begin{array}{l}\text { MGMT promoter } \\
\text { Methylated } \\
\text { Unmethylated }\end{array}$ & $\begin{array}{l}19 / 53 \\
34 / 53\end{array}$ & $\begin{array}{l}36 \\
64\end{array}$ & $\begin{array}{l}5 / 17 \\
12 / 17\end{array}$ & $\begin{array}{l}29.4 \\
70.6\end{array}$ \\
\hline Markers & & & & \\
\hline $\begin{array}{l}\text { clAP1 } \\
\text { Protein expression (positive/negative, range \%) } \\
\text { CIAP2 }\end{array}$ & $31 / 25(0-60)$ & $55.3 / 44.7$ & $19 / 19(0-30)$ & $50 / 50$ \\
\hline $\begin{array}{l}\text { Protein expression (positive/negative, range \%) } \\
\text { XIAP }\end{array}$ & $41 / 11(0-10)$ & $78.8 / 21.2$ & $6 / 31(0-15)$ & $16.2 / 83.8$ \\
\hline Protein expression (positive/negative, range \%) & 19/39 (0-90) & $32.7 / 67.3$ & $25 / 14(0-70)$ & $64.1 / 35.9$ \\
\hline $\begin{array}{l}M L-I A P \\
\quad \text { Protein expression (median, range \%) }\end{array}$ & $30(0-100)$ & & $15(0-80)$ & \\
\hline
\end{tabular}

including SMAC (second mitochondria-derived activator of caspase) released by the mitochondria during the apoptosis process. Small-molecule SMAC mimetics that mimic the $\mathrm{N}$-terminal part of the endogenous SMAC have been designed to antagonize IAPs and are currently under clinical considerations in some solid cancers (e.g., myeloma and ovarian cancers) and in lymphomas (ClinicalTrials.gov). ${ }^{10}$

For patients with GBM, the prognostic value of cIAP1, cIAP2, XIAP and ML-IAP expression remains to be determined. ${ }^{7,11}$ Therefore, in this study we investigated ex vivo the correlation between their expression levels and patient's survival in two retrospective cohorts in order to highlight the most interesting druggable targets. In order to assess the effect of SMAC mimetic on GBM tumors, we then tested in vitro the effect of GDC-0152 on four GBM cell lines. Finally, in vivo we treated GBM-bearing mice with GDC-0152 and determined the benefit of the treatment on survival and tumor growth.

\section{Results}

Correlation of IAP protein expression and GBM survival Cohort 1: CIAP1, cIAP2, XIAP and ML-IAP protein expression was first analyzed in a local monocentric cohort of 58 primary GBMs (Table 1). IAPs were heterogeneously expressed by tumor cells in GBM samples (Table 1). Stainings were diffused with a stronger punctuated positivity into the cytoplasm. clAP2 staining was sparser and was also found into some nuclei. Perivascular organization of ML-IAP-positive cells was often observed (Figure 1a).

As GBM samples expressed IAPs, we then tested for their prognostic values. The majority of samples expressing clAP1, clAP2 and XIAP did not exceed $30 \%$ of positive cells. Therefore, we analyzed their expression as positive or negative stainings for statistical relevance. In comparison, ML-IAP expression level was homogeneously distributed, allowing us to analyze its expression as a continuous variable.
As continuous variable, ML-IAP protein expression was significantly correlated to OS by Cox analysis $(P=0.005)$ : a smaller expression level was associated with a longer patient OS. Then, receiver operating characteristic (ROC) curve analysis was performed in order to determine an optimal cutoff for next univariate survival analyses. This ROC analysis allowed the determination of ML-IAP optimal cutoff of $35 \%$ of cell expression regarding OS ( $P=0.014$, AUC: 0.7$)$ (Supplementary Figure S1a). Regarding cIAP1, cIAP2 and XIAP studied as qualitative variables, they were dichotomized into positive and negative immunostainings. In univariate analyses, expression of ML-IAP of $\geqslant 35 \%$ was associated with worse prognosis (progression-free survival (PFS): $P=0.068$; OS: $P=0.008$; Figure $1 \mathrm{~b}$ ) and positive expression of XIAP (PFS: $P=0.057$; OS: $P=0.034$; Supplementary Figure $S 1 b$ ) was also associated with worse survival. In multivariate analysis (adjusted by Karnofsky Performance Status, gender and type of surgery), these results remained significant for OS (XIAP: $P=0.007$, hazard ratio (HR): $2.344(1.261-4.358)$ and ML-IAP: $P=0.003$, HR: 2.733 (1.415-5.279)). No prognostic value was found for clAP1 and clAP2 (Supplementary Figure S2).

Cohort 2: In order to validate our previous results, we identified a second independent local cohort of 43 GBMs (Table 1). In this cohort, only ML-IAP expression was correlated with survival in univariate (PFS, $P=0.001$ and OS, $P=0.007$; Figure 1c) and multivariate analyses, adjusted by age and type of surgery (PFS: $P=0.012, \mathrm{HR}: 3.585$ (1.320-9.738) and OS: $P=0.027$, HR: 3.09 (1.139-8.385); Supplementary Figure S2) confirming that ML-IAP protein expression is a significant factor of a poor prognosis in GBM. Of note, the pooled analysis of both cohorts 1 and 2 found similar results (Supplementary Figures S3a and b).

IAP protein expression in GBM cell lines. In order to determine whether we could detect the four IAPs in GBM cell 

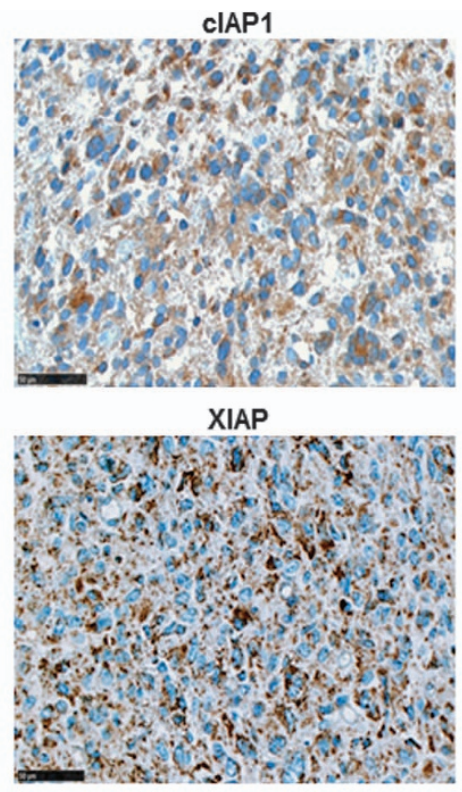

b
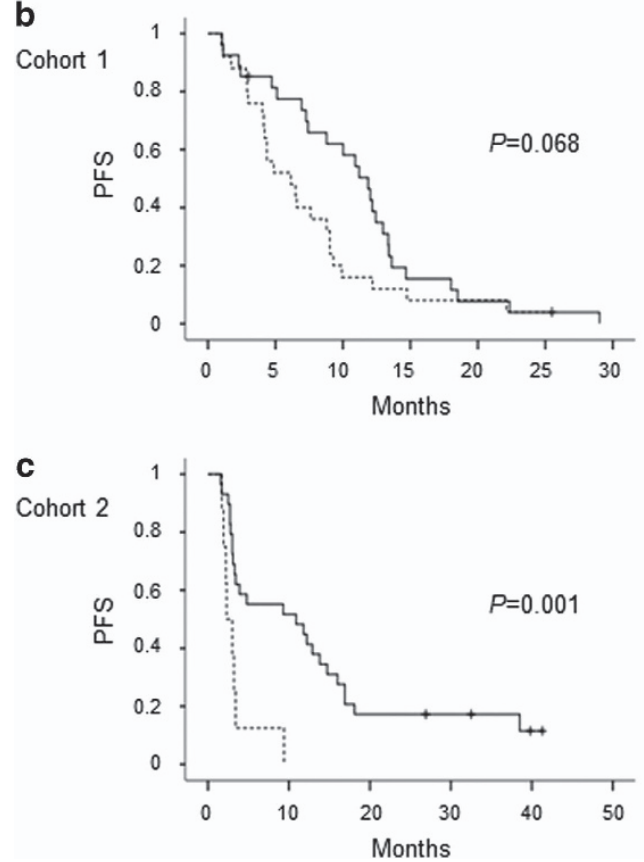

cIAP2

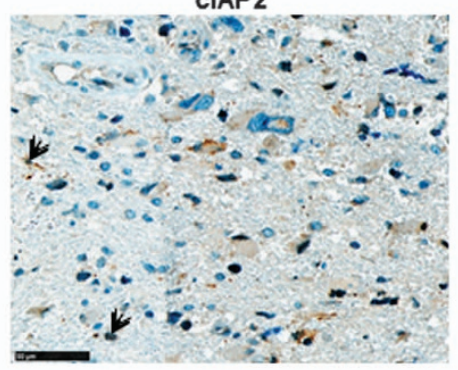

ML-IAP
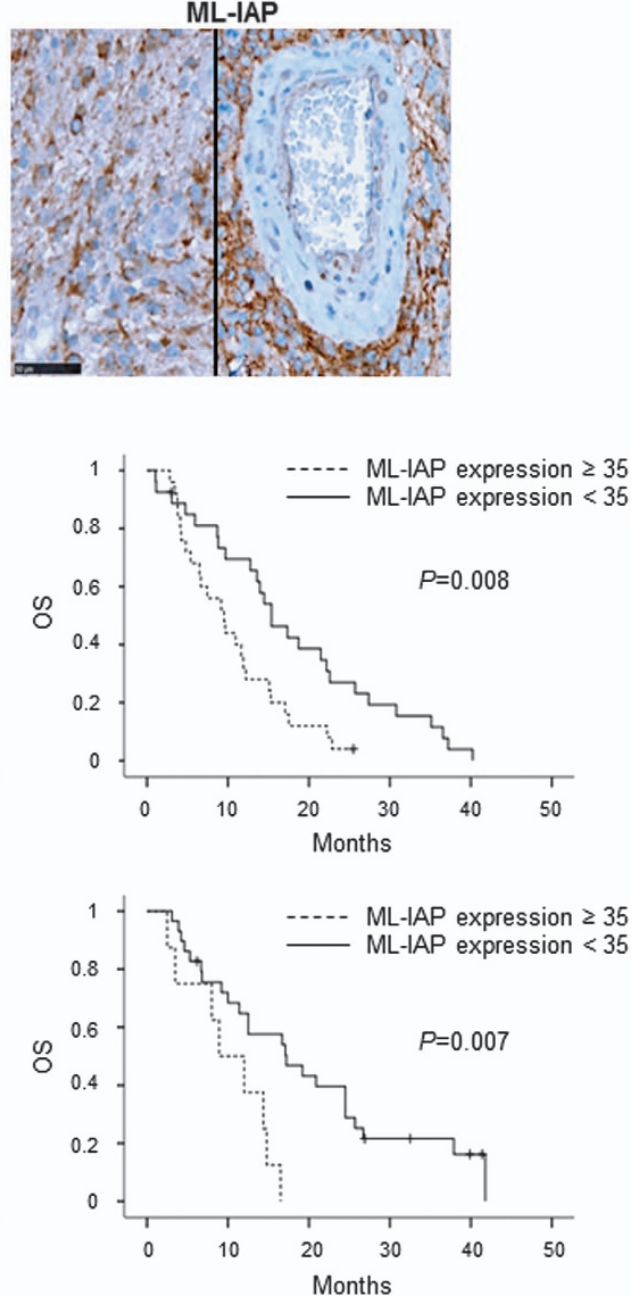

Figure 1 Prognostic value of cIAP1, CIAP2, XIAP and ML-IAP protein expression in human glioblastomas (cohorts 1 and 2). (a) cIAP1-, cIAP2-, XIAP- and ML-IAP-positive stainings in GBM. IAPs were heterogeneously expressed by tumor cells in GBM samples (Table 1). Stainings were diffused with a stronger punctuated positivity into the cytoplasm. Black arrows highlight clAP2-positive nuclei. Scale bars, $50 \mu \mathrm{m}$. (b) Correlation of ML-IAP protein expression with PFS and OS in cohort 1. The cutoff was $35 \%$ and was determined by performing a ROC curve. ML-IAP expression of $\geqslant 35 \%$ was correlated with a poor prognosis. (c) Correlation of ML-IAP protein expression with PFS and OS in cohort 2. The cutoff was the same as that for cohort 1 analysis (35\%). ML-IAP expression of $\geqslant 35 \%$ was correlated with a poor prognosis

lines, we analyzed their protein levels in U87MG, GL261, GBM6 and GBM9. The four GBM cell lines expressed IAPs at different levels (Figure 2). U87MG cells preferentially expressed XIAP, GL261 cells XIAP and ML-IAP, GBM6 CIAP1, CIAP2 and XIAP, and GBM9 XIAP and ML-IAP.

These results showed that these GBM cell lines expressed the four IAPs including ML-IAP and could therefore be used for further analyses.
Effect of SMAC mimetic GDC-0152 on cell viability and IAP protein expression in GBM cells. As we found that CIAP1, CIAP2, XIAP and ML-IAP were expressed in GBM and that ML-IAP was an independent factor of bad prognosis in patients, we tested a IAP antagonist targeting the four proteins. We selected a monovalent SMAC mimetic GDC-0152 described to antagonize clAP1, ClAP2, XIAP and, above all, ML-IAP. Moreover this compound was 

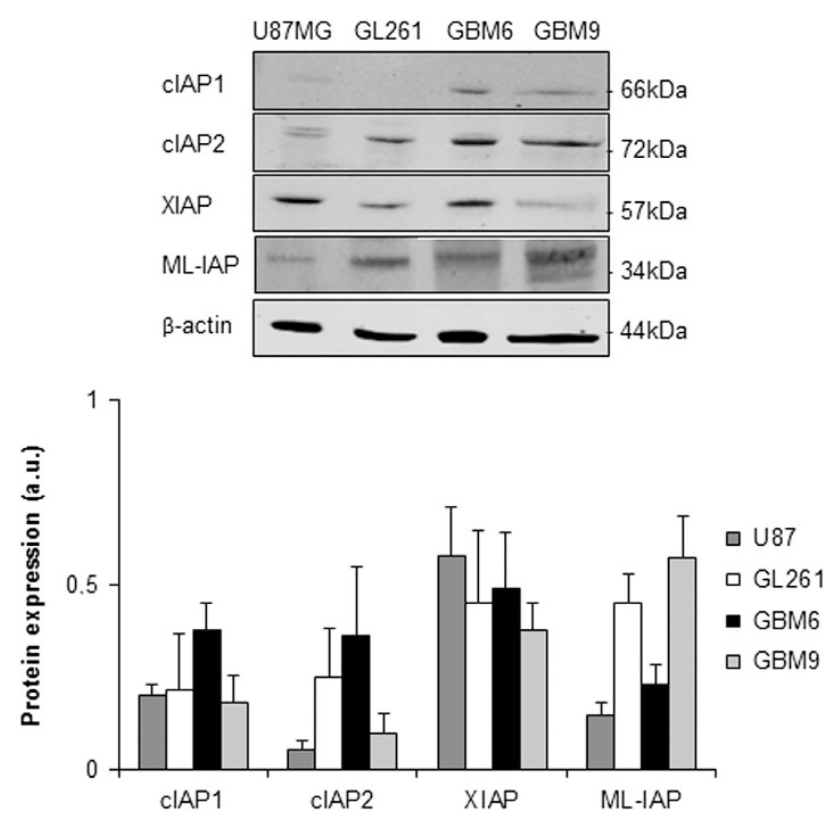

Figure 2 IAP expression in glioblastoma cell lines. Expression levels of CIAP1, CIAP2, XIAP and ML-IAP were analyzed by western blotting and quantified in U87MG and GL261 adherent GBM cell lines, and in GBM6 and GBM9 spheres. Expression level of $\beta$-actin served as loading control. The four GBM cell lines expressed heterogeneously cIAP1, CIAP2, XIAP and ML-IAP. A representative experiment of four experiments is shown. Quantification was performed using ImageJ software (National Institutes of Health, Bethesda, MD, USA) and data presented were normalized to $\beta$-actin expression

described to be suitable for both in vitro and in vivo studies with low toxicity. ${ }^{10}$

GDC-0152 affected U87MG and GL261 cell viability in timeand dose-dependent manner. We can notice that after $24 \mathrm{~h}$ of treatment GDC-0152 first increased survival in both cell lines. Cell viability started to decrease at $0.01 \mu \mathrm{M}$ for U87MG and at $0.5 \mu \mathrm{M}$ for GL261 after $72 \mathrm{~h}$ of treatment. In the same conditions, viability of GBM6 and GBM9 cell lines was barely affected (Supplementary Figure S4). After $72 \mathrm{~h}$ of treatment, GDC-0152 triggered 50\% of apoptosis in U87MG $(P=0.0079)$ and GL261 $(P=0.05)$ cell lines at $1 \mu \mathrm{M}$ and $100 \mu \mathrm{M}$, respectively. Eight days of treatment at $100 \mu \mathrm{M}$ of GDC-0152 were needed to reach $50 \%$ of apoptosis in GBM6 $(P=0.0079)$ and GBM9 $(P=0.0022)$ cell lines (Figure 3a). At these respective time points, GDC-0152 treatment decreased clAP1 and ML-IAP protein expression in U87MG cell line, clAP1, cIAP2 and XIAP in GL261 cell line and all IAP expression in GBM6 and GBM9 cell lines (Figure 3b).

Taken together, these results showed that GBM cell lines are sensitive to GDC-0152 treatment and that GDC-0152 is able to affect and decrease all IAP protein expression.

Effect of SMAC mimetic GDC-0152 on survival and tumor growth in vivo. As we showed that GBM cells were sensitive to GDC-0152 treatment, we decided to evaluate its antitumoral effect in vivo. A total of 21 mice were intracranially grafted with U87MG cells stably expressing near-infrared fluorescent protein (iRFP) in order to follow tumor growth in vivo as previously described. ${ }^{12}$ At 1 week after U87MG-
iRFP cell grafts, mice were treated either with vehicle (dimethyl sulfoxide (DMSO), $n=7)$ or with $10 \mathrm{mg} / \mathrm{kg}(n=7)$ or $20 \mathrm{mg} / \mathrm{kg}(n=7)$ of GDC-0152. Treatment started 1 week after cell injection and was performed once a week followed directly by tumor imaging. Treatment significantly increased mice survival in a dose-dependent manner $(P=0.01$; Figure 4a), postponed tumor formation and slowed down tumor growth (Figure 4b). Treatment was stopped when all the DMSO-treated mice were killed (60 days post injection) in order to test GDC-0152 long-term effect on the remaining mice. At weeks after the end of the treatment, only 1 out of 5 tumor-free mice developed a tumor in the ' $20 \mathrm{mg} / \mathrm{kg}$ ' group, suggesting a long-lasting efficiency of the treatment (Figure 4). All the remaining GDC-0152-treated mice were killed 3 weeks after the end of the treatment. Histological analyses were performed on brains to check for tumor formation. Hematoxylin and eosin colorations confirmed imaging results. All DMSO-treated brains showed a tumor, whereas tumors were present in 5 out of 7 and 3 out of 7 of ' $10 \mathrm{mg} / \mathrm{kg}$ ' and '20 mg/kg' groups, respectively, of GDC-0152treated brains. Differentiation and cell death showed respectively by glial fibrillary acidic protein (GFAP; $20 \mathrm{mg} / \mathrm{kg}$, $P=0.015)$ and cleaved caspase-3 (10 mg/kg, $P=0.03$; $20 \mathrm{mg} / \mathrm{kg}, P=0.028$ ) staining assays were increased in treated brains (Figures $5 \mathrm{a}$ and $\mathrm{b}$ ). Furthermore, cell proliferation was reduced in GDC-0152-treated tumors as shown by a decrease in Ki67 staining $(20 \mathrm{mg} / \mathrm{kg}, P=0.03$; Figures $5 \mathrm{a}$ and b). Importantly, ultrahigh performance liquid chromatography-selected reaction monitoring (UPLC-SRM) analysis clearly confirmed that GDC-0152 was able to cross the blood-brain barrier and to properly diffuse into the brain to target orthotopic GBM xenograft (Figure 6). Moreover, the average of mice weight was identical in treated and untreated animals (data not shown) and histological analysis of kidney, liver, lung, heart and brain did not demonstrate any difference among treated and untreated animals (data not shown). Taken together, these data showed that the GDC-0152 was not toxic at the concentrations used.

These results revealed that GDC-0152 treatment improved xenografted mice survival and slowed down GBM tumor growth.

\section{Discussion}

In this study, we highlighted the expression of clAP1, clAP2, XIAP and ML-IAP in an extensive cohort of human GBM. Moreover, we showed for the first time that ML-IAP was an independent prognostic marker in these tumors. Finally, our work also underscored the major role of IAPs in target therapy design as we showed the efficiency of SMAC mimetic GDC-0152 on GBM cell lines and GBM xenograft mice model.

Immunohistochemical detection of four IAPs in GBM showed that all cases expressed more than one IAP. Of particular interest was the expression of ML-IAP and high level was predictive of a worse prognosis. A previous study showed that ML-IAP was upregulated in GBM cell lines upon hypoxia leading to radio- and chemo-resistance. ${ }^{13}$ This previous work introduced ML-IAP as an actor of treatment resistance in GBM but the authors did not perform any correlation of ML-IAP expression with patient outcome. 


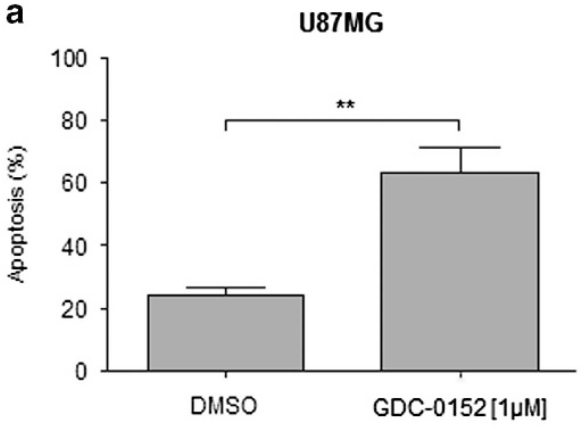

GL261

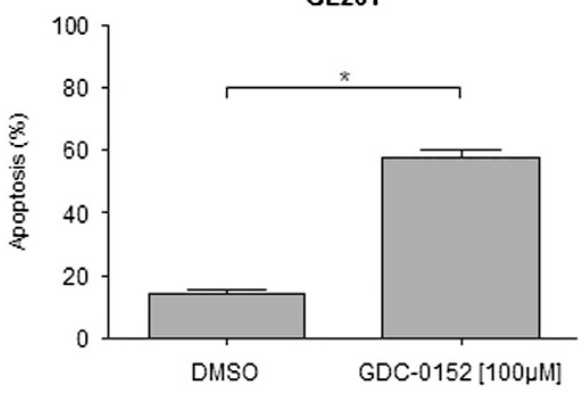

b

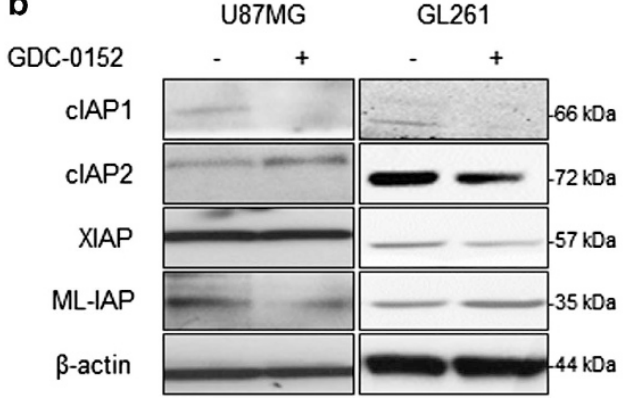

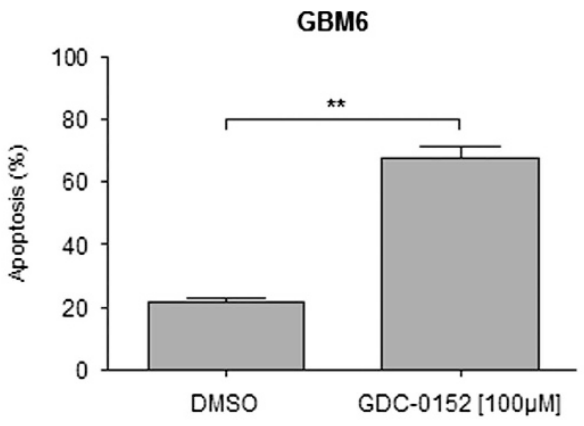

GBM9
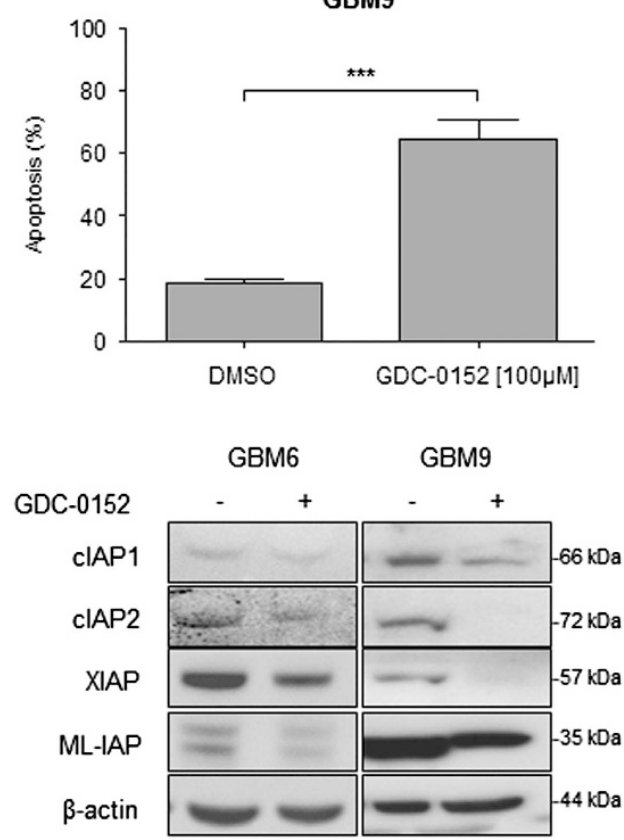

Figure 3 Apoptosis and IAP expression upon SMAC mimetic GDC-0152 treatment in glioblastoma cell lines. (a) Apoptosis (SubG0/G1) of DMSO control and GDC-0152treated cells was determined by flow cytometry of propidium iodide-stained nuclei and percentage of apoptosis is shown. U87MG and GL261 cell lines were treated for $72 \mathrm{~h}$ and GBM6 and GBM9 cell lines were treated for 8 days at the indicated concentrations. At these respective time points, percentage of U87MG cells dead by apoptosis, percentage of GL261 cells, percentage of GBM6 cells and percentage of GBM9 cells. Data are expressed as mean+S.E.M. Three independent experiments were performed for the GL261 cell lines and five for the U87MG, GBM6 and GBM9 cell lines. ${ }^{*} P<0.05$; ${ }^{\star \star} P<0.01 ;{ }^{* \star *} P<0.005$. (b) Expression levels of clAP1, cIAP2, XIAP and ML-IAP were analyzed by western blotting. Cell lines were treated with $1 \mu \mathrm{M}$ of GDC-0152. U87MG and GL261 were treated for $72 \mathrm{~h}$ and GBM6 and GBM9 cell lines for 8 days. In all GBM cell lines GDC-0152 decreased IAP expression. Expression level of $\beta$-actin served as loading control. A representative experiment of three experiments is shown

Because the standard of care for patients presenting a primary GBM is Stupp protocol, ${ }^{2}$ it is possible that the worse prognosis for patients with high ML-IAP level relies on in vivo radio- and chemo-resistance. Other studies have shown that ML-IAP expression was often associated with a bad prognosis in melanomas. ${ }^{14}$ In bladder cancer, ML-IAP expression was associated with early relapses ${ }^{15}$ and no correlation with patient outcome was found in other cancers. ${ }^{16-20}$ These results demonstrate the clinical relevance of using ML-IAP antagonist in GBM treatment.

In this study, we showed that GDC-0152, a SMAC mimetic used in monotherapy, demonstrated antitumoral effect in mouse orthotopic GBM xenograft model. Previous in vitro studies conducted on GBM showed that SMAC mimetics used in cotreatment sensitized GBM cells to temozolomide or $\gamma$-irradiations. ${ }^{21,22} \mathrm{~A}$ recent work described a reduction in U87MG tumor growth in an orthotopic mouse model when combined with Drozitumab, a TRAIL-R2 (Tumor-necrosisfactor-Related Apoptosis-Inducing Ligand Receptor 2). ${ }^{23}$ However, effect on survival of these combination treatments or SMAC mimetic alone was not evaluated in these studies. Moreover, the authors used the bivalent SMAC mimetic BV6 described to antagonize cIAP1, cIAP2 and XIAP. Because we clearly demonstrated the clinical relevance of ML-IAP expression in GBM, we chose in this study to analyze the effect of the monovalent SMAC mimetic GDC-0152 that is described to antagonize not only cIAP1, cIAP2, XIAP and also ML-IAP.

The in vitro studies in other cancers showed that GDC-0152 effect inhibited PI3K/Akt. In human leukemia cells, GDC-0152 downregulated cIAP1, CIAP2 and XIAP proteins and induced apoptosis through caspase- 9 and -3 activation and inhibition of PI3K/Akt pathway. ${ }^{24}$ In human osteosarcoma, GDC-0152 attenuated the metastasis properties of the SaOS2 cell line via PI3K/Akt inhibition. ${ }^{25}$ We showed here that GDC-0152 


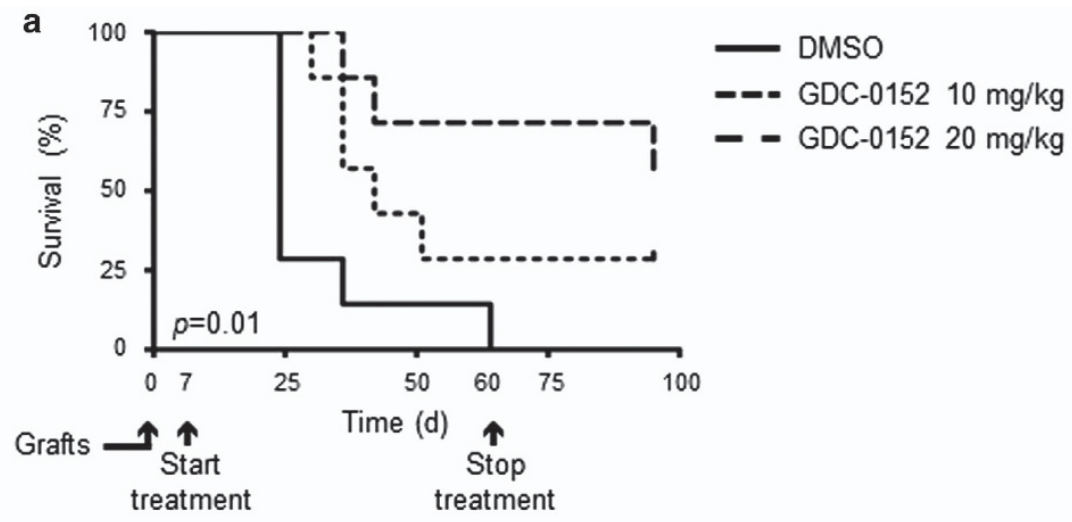

b
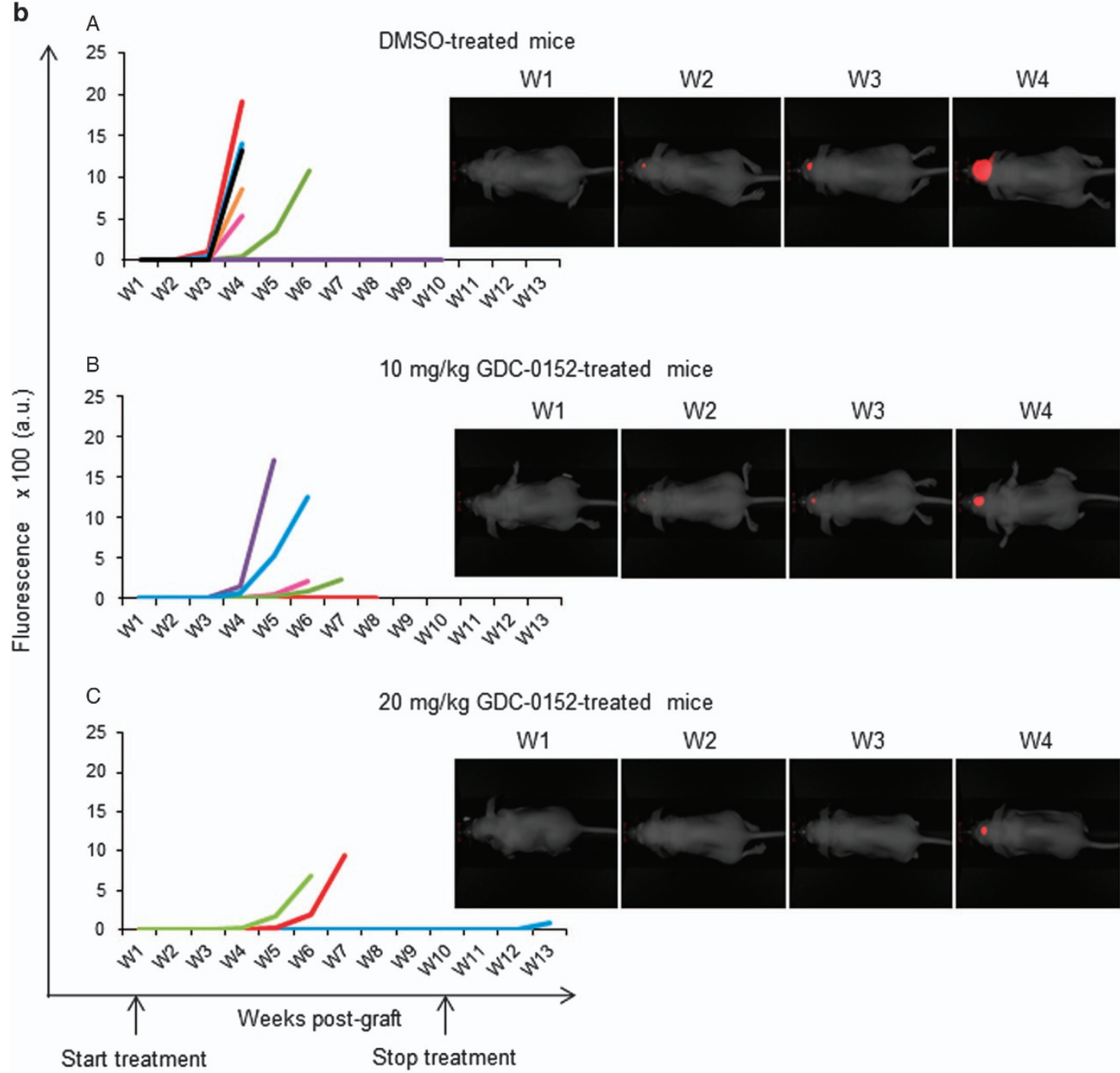

W3
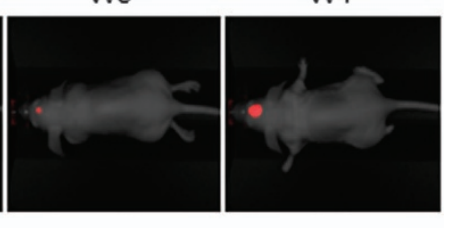

W3
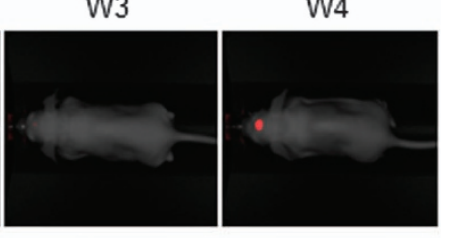

Figure 4 Effect of SMAC mimetic GDC-0152 on survival and tumor growth of mice bearing intracranial tumors. (a) A total of 100000 U87MG-iRFP cells were injected into the corpus callosum of athymic nude mice. At 1 week after injection, mice were treated either with DMSO $(n=7)$ or $10 \mathrm{mg} / \mathrm{kg}(n=7)$ or $20 \mathrm{mg} / \mathrm{kg}(n=7)$ of GDC-0152. OS curves of mice were estimated by the Kaplan-Meier method. GDC-0152 increased mice survival in a dose-dependent manner. (b) Images of representative U87MG-iRFP tumors

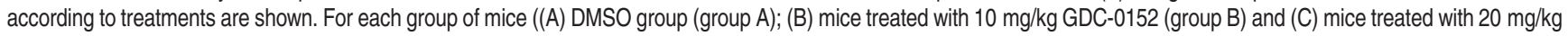
GDC-0152 (group C)), graphs represent the normalized growth curve for each animal that developed a tumor. In addition, we observed that 7/7 mice developed a tumor in group $A, 5 / 7$ in group $B$ and $3 / 7$ in group $C$. In this group one mouse developed a tumor 2 weeks after the end of treatment (blue line). The mouse representative of the DMSO group corresponds to the black line; the mouse representative of the $10 \mathrm{mg} / \mathrm{kg} \mathrm{GDC}-0152$ corresponds to the blue line; the mouse representative of the $20 \mathrm{mg} / \mathrm{kg}$ GDC-0152 corresponds to the green line. W, weeks. GDC-0152 treatment slowed down tumor growth 
a

DMSO

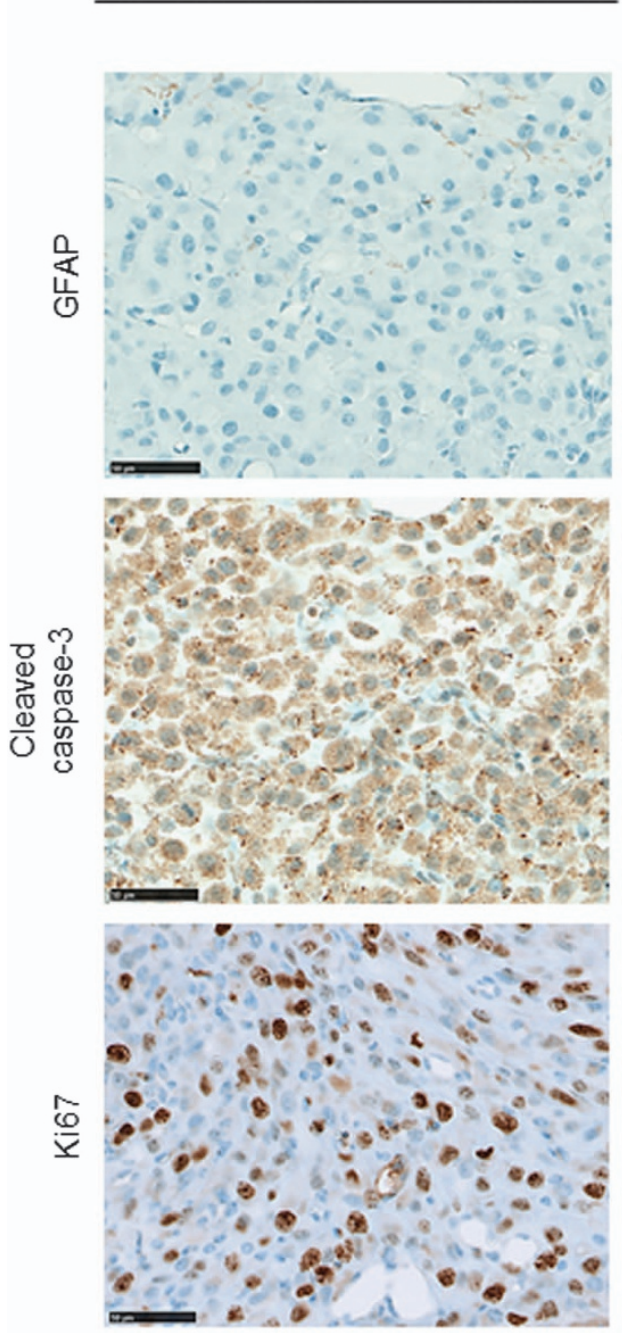

b

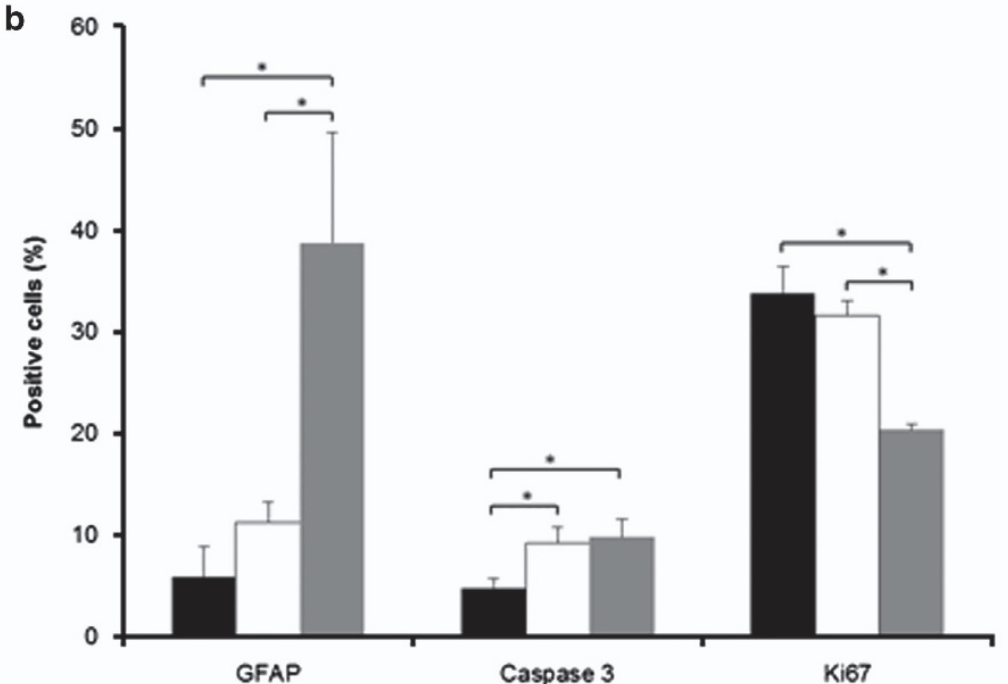

GDC-0152
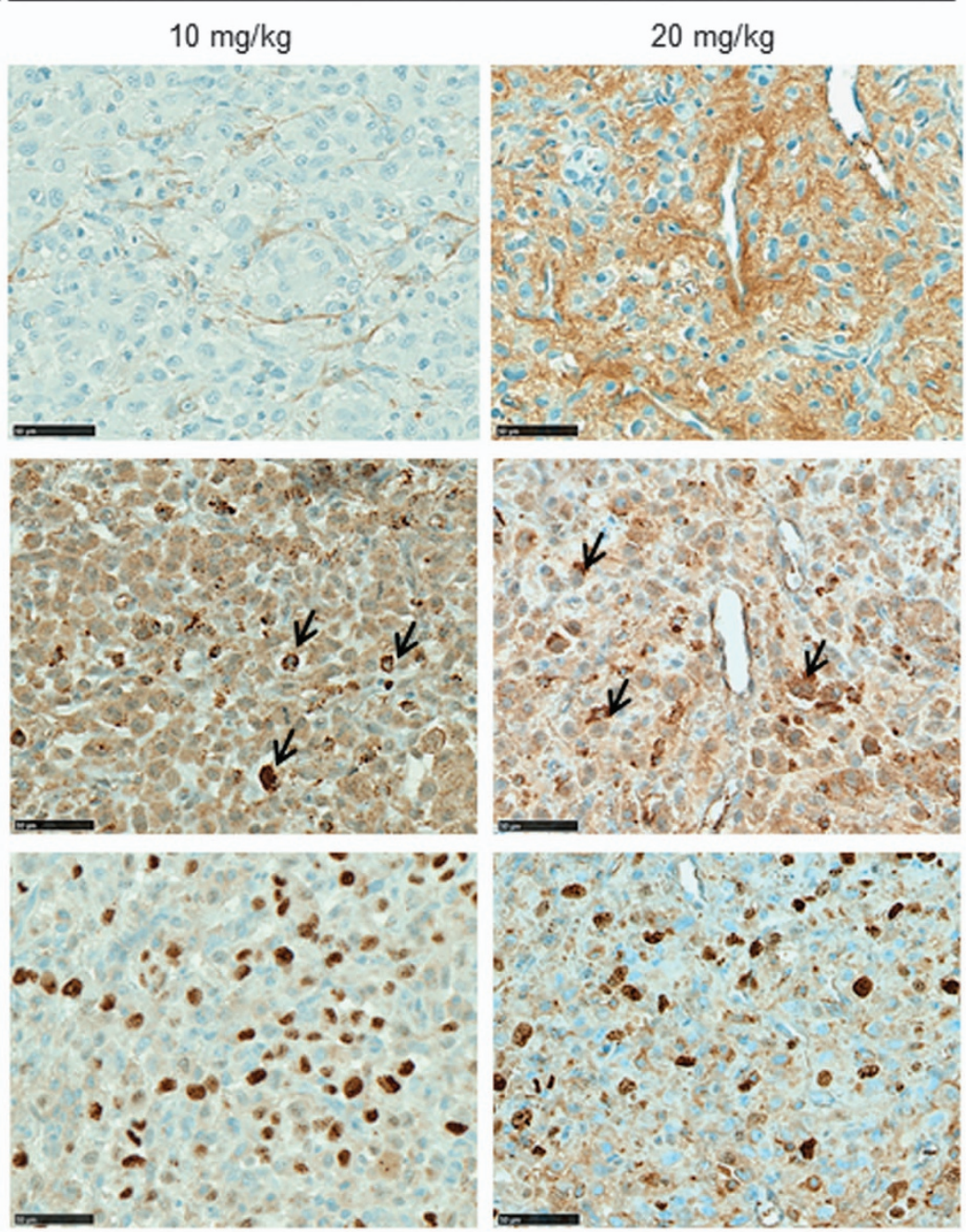

- DMSO

口 GDC-0152 $10 \mathrm{mg} / \mathrm{kg}$

- GDC-0152 $20 \mathrm{mg} / \mathrm{kg}$

Figure 5 Immunohistochemistry analysis of mice-treated brains. (a) Representative GFAP, cleaved caspase-3 and Ki67 stainings of tumors treated with DMSO and 10 and $20 \mathrm{mg} / \mathrm{kg}$ of GDC-0152. Black arrows highlight apoptotic cells. Scale bars, $50 \mu \mathrm{m}$. (b) Quantification of the percentage of GFAP-, cleaved-caspase-3- and Ki67-positive cells in tumors treated with DMSO and 10 and $20 \mathrm{mg} / \mathrm{kg}$ of GDC-0152. Differentiation and cell death showed respectively by GFAP and cleaved caspase-3 stainings were increased in GDC-0152-treated brains. Cell proliferation was reduced in GDC-0152-treated tumors as shown by a decrease in Ki67 staining. Mean+S.E.M. are shown. ${ }^{*} P<0.05$ 


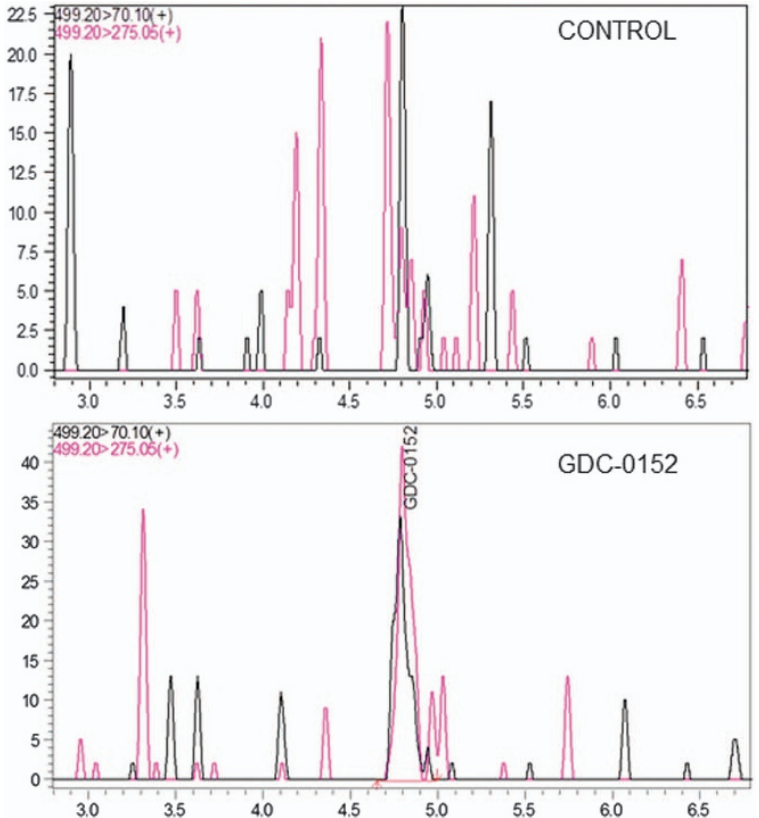

Figure 6 Multiple reaction monitoring (MRM) chromatograms of FFPE tissue extracts from control mouse brain (upper) and GDC-0152-treated mouse brain (lower). Linearity: Standard curve was obtained by linear regression using external calibration with 5 points in the range of 1 to $100 \mathrm{ng} / \mathrm{ml}$. The calibration curve was linear over the range of 1 to $100 \mathrm{ng} / \mathrm{ml}$ with a mean correlation coefficient of 0.999 . Quantification was achieved using peak area of compounds interpolated from the standard curve. Optimization: Extraction recoveries and feasibility were estimated comparing control FFPE brain tissue sections spiked with $5 \mu \mathrm{l}$ of $50 \mathrm{ng} / \mathrm{ml}$ of GDC-0152 and control sections spiked with just the solvent. Detection of GDC-0152 in treated FFPE mouse brain sections. The limit of detection corresponds to a signal to noise $(\mathrm{S} / \mathrm{N})$ ratio of $\geqslant 3$. The result obtained shows a detection of GDC-0152 in treated brains compared with control

increased apoptosis and differentiation in all GBM cell lines. This effect was also observed in xenografts model. However, which signaling pathway is involved needs to be investigated.

Besides their anti-apoptotic function, IAPs have a broader role in tumorigenesis. We previously reported non-apoptotic functions of SMAC mimetics in GBM migration and GBM stem cell differentiation. ${ }^{26}$ Here, well-circumscribed tumors were obtained in DMSO control as well as in GDC-0152-treated mice showing no difference on cell migration/invasion upon GDC-0152 treatment. We previously reported that SMAC mimetic BV6 was able to reduce GBM stem-like cell properties in vitro and in vivo. After in vitro BV6 treatment, GBM stem-like cells were grafted orthotopically and lost their tumorigenic potential. ${ }^{26}$ We could not learn from this study whether GDC-0152 in monotherapy triggered GBM stem-like cells in vivo. It was obvious however that the two GBM cancer stem cell lines GBM6 and GBM9 were more resistant to GDC-0152 treatment in vitro than U87MG and GL261 cell lines.

Beyond effects in GBM cells, whether GDC- 0152 would also activate apoptotic and non-apoptotic effects on other cellular compartments such as microenvironment remains to be determined.

SMAC mimetics are not tested yet in clinical trials for GBM and the present work underlines the need of such investigations. As SMAC mimetics are already under clinical investigations in other cancers, translation into clinic would be facilitated and attractive. As we demonstrated that ML-IAP is a particular attractive target, development of more specific ML-IAP antagonist would therefore be relevant.

\section{Materials and Methods Human glioblastoma samples}

Local GBM cohort. GBM tumor specimens were obtained according to a protocol approved by the local institutional review board and ethics committee (2014-A00585-42) and conducted according to national regulations. All the patients provided written informed consent. Patient characteristics are summarized in Table 1. GBM formalin-fixed, paraffin-embedded (FFPE) samples provided by the AP-HM tumor bank (authorization AC-2013-1786) were pooled on several tissuemicroarrays (TMAs) for high-throughput screening. Areas of viable and representative tumor following review of all blocks were marked by a pathologist (DF-B) before inclusion into the TMA $(3 \times 0.6 \mathrm{~mm}$ cores for each tumor). The first TMA cohort consisted of 58 patients with newly diagnosed IDH1/2 wild-type GBM for whom clinical data were available.

In view of the results observed in the first cohort, we identified a second independent TMA cohort of 43 patients with IDH1/2 wild-type GBM with available clinical data (Table 1).

Immunohistochemistry and immunostaining quantification. After steam-heat-induced antigen retrieval, $5 \mu \mathrm{m}$ sections of FFPE samples were tested for the presence of CIAP1 (Rabbit polyclonal IgG AF8181, R\&D Systems, Wiesbaden, Germany), cIAP2 (Mouse IgG AF8171, R\&D Systems), XIAP (Mouse $\lg \mathrm{G} 1$, clone 48, BD Biosciences, Franklin Lake, NJ, USA), ML-IAP (Mouse IgG1, IMG-347A, Imegenex, Cambridge, UK), GFAP (EP672Y, Ventana Medical Systems, Illkirch, France), Ki67 (30-9, Ventana Medical Systems) and caspase-3 (C92605, BD Biosciences). A Benchmark Ventana autostainer (Ventana Medical Systems) was used for detection, and slides were simultaneously immunostained in order to avoid intermanipulation variability. For negative controls, irrelevant antibodies with identical isotypes were used. Slides were then scanned (Nanozoomer 2.0-HT, Hamamatsu Photonics SARL France, Massy, France) and images processed in NDP.view2 software (Hamamatsu).

Based on immunostaining results, ML-IAP positivity was determined as percentage of positive cells and CIAP1, CIAP2 and XIAP were quantified as positive or negative staining. The percentage of GFAP-, Ki67- or cleaved-caspase-3-positive cells was determined as previously described. ${ }^{26}$

Cell lines and reagents. GBM6 and GBM9 GBM stem cell lines were isolated in the laboratory from two different human GBM tumor samples and exhibited features reminiscent of the clinical characteristics of the original tumors respectively. ${ }^{27}$ These cells were grown as floating spheres in serum-free medium supplemented with epidermal growth factor (EGF) and basic fibroblast growth factor (bFGF) as previously described. ${ }^{28}$ For GDC-0152 treatment experiments, cells were grown in the same medium on $10 \mu \mathrm{g} / \mathrm{ml}$ poly-DL-ornithin in order to allow cells to attach to the plastic without differentiating. Human GBM cell line U87MG (American Type Culture Collection, Rockville, MD, USA) and murine GBM cell line GL261 (gift from $\mathrm{F}$ Debarbieux, Aix-Marseille University, France) were cultured as monolayers respectively in Dulbecco's modified Eagle's medium (DMEM; Life Technologies, Saint Aubin, France) and RPMI (Life Technologies) supplemented with 10\% fetal calf serum, $50 \mathrm{U} / \mathrm{ml}$ penicillin and $50 \mu \mathrm{g} / \mathrm{ml}$ streptomycin. All the cell lines were grown at $37{ }^{\circ} \mathrm{C}$ in a humidified atmosphere of $5 \% \mathrm{CO}_{2}$ and $95 \%$ air.

Monovalent SMAC mimetic GDC-0152 (Selleckchem, Houston, TX, USA) was dissolved at $30 \mathrm{mM}$ for in vitro studies and $50 \mathrm{mM}$ for in vivo studies in DMSO (SigmaAldrich, Saint-Quentin Fallavier, France) and stored at $-80^{\circ} \mathrm{C}$ until use.

Cell viability assay. Effect of GDC-0152 on U87MG, GL261, GBM6 and GBM9 cell line viability was evaluated by assessing cell metabolic capacity using the MTT method (3-(4,5-dimethylthiazol-2yl)-diphenyl tetrazolium bromide; SigmaAldrich). GBM6 and GBM9 were seeded in previously poly-DL-ornithin-coated 96-well plates $(10000,8000$ and 6000 cells per well for 24,48 and $72 \mathrm{~h}$ of treatment, respectively). U87MG and GL261 were seeded in 96-well plates (8000, 6500 and 5000 cells per well). After $24 \mathrm{~h}$, cells were treated with serial concentrations of GDC-0152 $(0.01,0.05,0.1,0.5,1,5,10$ and $20 \mu \mathrm{M})$ in $200 \mu \mathrm{l}$ of cell-specific media per well. After treatment, $20 \mu \mathrm{l}$ of MTT reagent was added to each well and plates were incubated for $4 \mathrm{~h}$ at $37^{\circ} \mathrm{C}$. The reduced formazan was 
dissolved in $200 \mu \mathrm{l}$ of DMSO and absorbance was measured at $562 \mathrm{~nm}$ with an Elx800 microplate reader (Bio-Tek, Colmar, France) and data were analyzed with Gen5 1.09 software (Bio-Tek).

DNA fragmentation. Apoptosis was determined by flow cytometric analysis (FACSCalibur, BD Biosciences) of DNA fragmentation of propidium iodide-stained nuclei as described previously. ${ }^{29-31}$ U87MG and GL261 cell lines were seeded in 12-well plate (40 000 and 60000 per well respectively), and $24 \mathrm{~h}$ after seeding, cells were treated with GDC-0152 for $72 \mathrm{~h}$. GBM6 and GBM9 were seeded in previously poly-DL-ornithin-coated 12-well plate (25000 per well) for 8 days of GDC-0152 treatment. Cells were fixed and permeabilized with $70 \%$ ethanol. The cells were then centrifuged, washed in phosphate-buffered saline (PBS) and resuspended in PBS supplemented with RNAse A ( $50 \mu \mathrm{g} / \mathrm{ml})$ and propidium iodide $(40 \mu \mathrm{g} / \mathrm{ml})$. Cells were incubated in the dark at room temperature for $15 \mathrm{~min}$ and rapidly analyzed. Results were harvested with the CellQuest Pro Software (BD Biosciences) and analyzed using FlowJo software (Ashland, OR, USA).

Protein extraction and western blotting. Proteins were extracted with tris(hydroxymethyl)-aminomethane hydrochloric acid (Tris- $\mathrm{HCl})$ pH $7.4(50 \mathrm{nM})$, $\mathrm{NaCl}$ ([250 mM), EDTA (5 mM), dithiothreitol (DTT; $1 \mathrm{nM}), 1 \%$ Triton X-100, $0.1 \%$ SDS (1 M), $0.5 \%$ sodium deoxycholate, $1 \%$ Nonidet P-40 (NP-40) and Complete $1 \times$ (Roche Applied Science, Meylan, France). After two sonications, cells were maintained 20 min on ice and centrifuged for 10 min at 12000 revolutions per min (r.p.m.). Protein concentration was assayed using bicinchoninic acid (MicroBCA kit, Pierce, Rockford, IL, USA). Then, $50 \mu \mathrm{g}$ proteins per lane were separated by $12 \%$ sodium dodecylsulfate-polyacrylamide gel electrophoresis (SDS-PAGE) and transferred onto nitrocellulose membrane (iBlot gel transfer, Life Technologies). After blocking for $2 \mathrm{~h}$ in PBS supplemented with $5 \%$ skimmed milk, immunodetection was performed using anti-cIAP1 (1 : 1000, AF8181, R\&D Systems), anti-clAP2 (1: 1000, clone E40, Epitomics, Burlingame, CA, USA), anti-XIAP (1 : 1000, clone 28, BD Biosciences), anti-ML-IAP (1:1000, clone 88C570, Imgenex, San Diego, CA, USA) and anti- $\beta$-actin (1:5000, Sigma-Aldrich) in PBS supplemented with $5 \%$ bovine serum albumin (BSA) and $0.1 \%$ Tween-20 (Sigma-Aldrich), followed by horseradish peroxidase-conjugated goat anti-mouse IgG (Santa Cruz Biotechnology, Santa Cruz, CA, USA) or rabbit anti-goat IgG (Dako France, Ulis, France). ECL (Bio-Rad, Marne-la-Coquette, France) was used for detection.

iRFP infection. The HIV-derived lentiviral vector encompassing the iRFP complementary DNA (CDNA), viral particle preparation and cell transduction were performed essentially as described. ${ }^{12}$ Briefly, the iRFP construct was made by replacing the enhanced green fluorescent protein (EGFP) gene in the lentiviral vector pRRLSIN.CPPT.PGK-GFP.WPRE ${ }^{32}$ (referred to as pRRL) by the iRFP cDNA originating from the pShuttle-CMV-iRFP plasmid (a gift of Dr. Verkhusha, Addgene plasmid 31856, Teddington, UK). In order to easily monitor transfection and transduction events, we chose the simultaneous expression of iRFP and the red fluorescent protein mCherry (Clonetech, Mountain View, CA, USA) using the internal ribosomal entry sequence (IRES) system. For this purpose the IRESmCherry DNA cassette was cut from pcDNA3/IFP1.4 (kindly provided by Dr. Tsien, Scripps Clinic, La Jolla, CA, USA) with Xhol and BsrGl and cloned at the $3^{\prime}$ end of the iRFP sequence between Sall and Acc651 sites, giving rise to pRRL/iRFP/IRESmCherry, thus driving the expression of a single bicistronic mRNA encoding both IRFP and mCherry. Lentiviral particles preparation and infection of the human GBM U87MG cells with viral particles were performed according to Mathieu et al..$^{33}$

Intracranial injections. All experimental procedures using animals were carried out according to a protocol approved by institutional review board and the French ethical committee. This project received the authorization number 02313.01. A total of 100000 U87MG-iRFP cells were stereotactically injected in the corpus callosum $(+1 \mathrm{~mm}$ anterior to bregma, $-1 \mathrm{~mm}$ lateral and $-2 \mathrm{~mm}$ in deep of the cortex surface) of 216 -week-old athymic nude mice as previously described. ${ }^{28}$ Animals were observed until they fully recovered. The body weight and clinical status of mice were recorded every 2 days. Mice were killed when they exhibited $>20 \%$ reduction from initial body weight or significant neurological deficit. Mice were weekly intravenously treated with GDC-0152 (10 and $20 \mathrm{mg} / \mathrm{kg}$ ) or with vehicle (highest volume of DMSO). Treatment started 1 week after cell graft and was stopped when all the DMSO-treated mice were killed (60 days post graft). These concentrations were previously reported to be nontoxic in dogs and rats, ${ }^{10,34,35}$ but, to our knowledge, no data regarding toxicity in mice were available in literature. Directly after their killing, brains were extracted, fixed in formalin and paraffin embedded according to standard procedures. In addition, we also collected liver, kidney, lung, heart and brain from 3 control mice and 3 mice treated with $20 \mathrm{mg} / \mathrm{kg}$ GDC-0152 to check cell toxicity on selected organs. Hematoxylin and eosin colorations were performed on $5 \mu \mathrm{m}$ sections of FFPE brains in order to validate tumor development.

UPLC-SRM. Two pools of mice grafted with U87MG-iRFP and demonstrating brain tumors were used. Twenty sections from FFPE tissue blocks of GDC-0152 treated mice and of DMSO control mice were deparaffinized by incubating with $1 \mathrm{ml}$ of xylen for $10 \mathrm{~min}$ at room temperature followed by centrifugation at $20000 \times \mathrm{g}$ for $5 \mathrm{~min}$. The supernatant was collected and transferred to a clean Eppendorf tube. The extract was dried in a concentrator. The dry extracts was then suspended in $20 \mu \mathrm{l}$ of acetonitrile/ $0.1 \%$ formic acid $(50: 50)$.

UPLC-SRM was performed on a Nexera LC system (Shimadzu Corporation, Tokyo, Japan) coupled to a Triple quadripole 8040 mass spectrometry system (Shimadzu Corporation). Separation of GDC-0152 was carried out using a Kinetex XB-C18 column $(150 \times 2.1 \mathrm{~mm}), 2.6 \mu \mathrm{m}$ particle size, Phenomenex with a column temperature of $30{ }^{\circ} \mathrm{C}$. Elution was obtained by a linear gradient from 5 to $50 \%$ of acetonitrile in $0.1 \%$ formic acid over $6 \mathrm{~min}$ at a flow rate of $0.4 \mathrm{ml} / \mathrm{min}$. Next, $5 \mu \mathrm{l}$ of the extract was injected on the UPLC-SRM. After automatic optimization of collision energies for GDC-0152, the transitions were set to 499.2-> 275 and 499.2-> 70.1. Data acquisition and analysis were performed using Labsolution v5.6 software from Shimadzu Corporation.

In vivo imaging and analysis. Image acquisition of U87MG-iRFP-injected mice was taken directly after treatment with a Pearl Impulse Small Animal Imaging System (Li-Cor Biosciences GmbH, Bad Hamburg, Germany) and the analysis was performed using Image Studio Lite software (Li-Cor Biosciences $\mathrm{GmbH}$ ) as previously described. ${ }^{12}$ Images of all mice were linked in order to apply the same fluorescence intensity settings. Data were then normalized to the background and to the lowest fluorescence intensity, and are presented as arbitrary units (a.u.) according to Filonov et al. ${ }^{36}$

Statistical analysis. Categorical variables were presented as frequencies and percentages and continuous variables as median and range. OS was defined to be time from the date of surgery to death, censored at the date of last contact. PFS was defined to be time from the date of surgery to documented progression or death, censored at the date of the last documented disease evaluation. The Kaplan-Meier method was used to estimate survival distributions. Log-rank tests were used for univariate comparisons. Cox proportional hazards models were used for continuous and multivariate analyses and to estimate HRs in survival regression model. Multivariate analysis included all variables (gender, age, KPS and type of surgery) with a $P$-value of $<0.05$. Mann-Whitney U-test was used to compare quantitative values; qualitative values were compared using the $\chi^{2}$ test or Fisher's exact test. For survival analyses, subjects were divided into two groups based on their optimal cutoff determined by the ROC analysis for the quantitative variable (ML-IAP) or into positive and negative groups for the qualitative variables (cIAP1, cIAP2 and XIAP). All the tests were two sided and $P$-values of $<0.05$ were considered significant for each statistical analysis.

Statistical analyses were conducted using the statistical package SPSS software v.22 (SPSS Inc., Chicago, IL, USA).

\section{Conflict of Interest}

The authors declare no conflict of interest.

Acknowledgements. This study was supported by Institut National du Cancer (Grant INCa-DGOS-Inserm 6038) and institutional grants (Inserm, Aix-Marseille University). A Soubéran and E Denicolai are supported by the Association pour la Recherche sur les Tumeurs Cérébrales (ARTC-Sud). We thank M Cayol for mice handling and S Mathieu for technical advices.

1. Louis DN, Perry A, Reifenberger G, von Deimling A, Figarella-Branger D, Cavenee WK et al. The 2016 World Health Organization Classification of Tumors of the Central Nervous System: a summary. Acta Neuropathol 2016; 131: 803-820.

2. Stupp R, Mason WP, van den Bent MJ, Weller M, Fisher B, Taphoorn MJ et al. Radiotherapy plus concomitant and adjuvant temozolomide for glioblastoma. N Engl J Med 2005; 352: 987-996. 
3. Chinot OL, Wick W, Mason W, Henriksson R, Saran F, Nishikawa R et al. Bevacizumab plus radiotherapy-temozolomide for newly diagnosed glioblastoma. N Engl J Med 2014; 370 : 709-722.

4. Gilbert MR, Sulman EP, Mehta MP. Bevacizumab for newly diagnosed glioblastoma. N Engl J Med 2014; 370: 2048-2049.

5. Hanahan D, Weinberg RA. Hallmarks of cancer: the next generation. Cell 2011; 144 646-674.

6. Fulda S, Vucic D. Targeting IAP proteins for therapeutic intervention in cancer. Nat Rev Drug Discov 2012; 11: 109-124.

7. Chakravarti A, Noll E, Black PM, Finkelstein DF, Finkelstein DM, Dyson NJ et al. Quantitatively determined survivin expression levels are of prognostic value in human gliomas. J Clin Oncol 2002; 20: 1063-1068.

8. Shi YH, Ding WX, Zhou J, He JY, Xu Y, Gambotto AA et al. Expression of X-linked inhibitorof-apoptosis protein in hepatocellular carcinoma promotes metastasis and tumor recurrence. Hepatology 2008; 48: 497-507.

9. Feltham R, Khan N, Silke J. IAPS and ubiquitylation. IUBMB Life 2012; 64: 411-418,

10. Flygare JA, Beresini M, Budha N, Chan H, Chan IT, Cheeti S et al. Discovery of a potent small-molecule antagonist of inhibitor of apoptosis (IAP) proteins and clinical candidate for the treatment of cancer (GDC-0152). J Med Chem 2012; 55: 4101-4113.

11. Preusser M, Gelpi E, Matej R, Marosi C, Dieckmann K, Rossler K et al. No prognostic impact of survivin expression in glioblastoma. Acta Neuropathol 2005; 109: 534-538.

12. Jiguet-Jiglaire $C$, Cayol M, Mathieu $S$, Jeanneau $C$, Bouvier-Labit $C$, Ouafik $L$ et al. Noninvasive near-infrared fluorescent protein-based imaging of tumor progression and metastases in deep organs and intraosseous tissues. J Biomed Opt 2014; 19: 16019.

13. Hsieh CH, Lin YJ, Wu CP, Lee HT, Shyu WC, Wang CC. Livin contributes to tumor hypoxiainduced resistance to cytotoxic therapies in glioblastoma multiforme. Clin Cancer Res 2015; 21: $460-470$.

14. Zhou J, Yuen NK, Zhan Q, Velazquez EF, Murphy GF, Giobbie-Hurder A et al. Immunity to the melanoma inhibitor of apoptosis protein (ML-IAP; livin) in patients with malignant melanoma. Cancer Immunol Immunother 2012; 61: 655-665.

15. Gazzaniga P, Gradilone A, Giuliani L, Gandini O, Silvestri I, Nofroni I et al. Expression and prognostic significance of LIVIN, SURVIVIN and other apoptosis-related genes in the progression of superficial bladder cancer. Ann Oncol 2003; 14: 85-90.

16. Kim DK, Alvarado CS, Abramowsky CR, Gu L, Zhou M, Soe MM et al. Expression of inhibitor-of-apoptosis protein (IAP) livin by neuroblastoma cells: correlation with prognostic factors and outcome. Pediatr Dev Pathol 2005; 8: 621-629.

17. Tanabe $H$, Yagihashi A, Tsuji N, Shijubo $Y$, Abe S, Watanabe N. Expression of survivin mRNA and livin mRNA in non-small-cell lung cancer. Lung Cancer 2004; 46: 299-304.

18. Takeuchi H, Kim J, Fujimoto A, Umetani N, Mori T, Bilchik A et al. X-linked inhibitor of apoptosis protein expression level in colorectal cancer is regulated by hepatocyte growth factor/C-met pathway via Akt signaling. Clin Cancer Res 2005; 11: 7621-7628.

19. Xiang Y, Yao H, Wang S, Hong M, He J, Cao S et al. Prognostic value of Survivin and Livin in nasopharyngeal carcinoma. Laryngoscope 2006; 116: 126-130.

20. Takeuchi H, Morton DL, Elashoff D, Hoon DS. Survivin expression by metastatic melanoma predicts poor disease outcome in patients receiving adjuvant polyvalent vaccine. Int $J$ Cancer 2005; 117: 1032-1038.

21. Berger R, Jennewein C, Marschall V, Karl S, Cristofanon S, Wagner L et al. NF-kappaB is required for Smac mimetic-mediated sensitization of glioblastoma cells for gammairradiation-induced apoptosis. Mol Cancer Ther 2011; 10: 1867-1875.

22. Wagner L, Marschall V, Karl S, Cristofanon S, Zobel K, Deshayes K et al. Smac mimetic sensitizes glioblastoma cells to Temozolomide-induced apoptosis in a RIP1- and NFkappaB-dependent manner. Oncogene 2013; 32: 988-997.

23. Cristofanon S, Abhari BA, Krueger M, Tchoghandjian A, Momma S, Calaminus C et al. Identification of RIP1 as a critical mediator of Smac mimetic-mediated sensitization of glioblastoma cells for Drozitumab-induced apoptosis. Cell Death Dis 2015; 6: e1724.
24. Hu R, Li J, Liu Z, Miao M, Yao K. GDC-0152 induces apoptosis through down-regulation of IAPs in human leukemia cells and inhibition of PI3K/Akt signaling pathway. Tumour Biol $2015 ; 36: 577-584$

25. Yang L, Shu T, Liang Y, Gu W, Wang C, Song X et al. GDC-0152 attenuates the malignant progression of osteosarcoma promoted by ANGPTL2 via PI3K/AKT but not p38MAPK signaling pathway. Int J Oncol 2015; 46: 1651-1658.

26. Tchoghandjian A, Jennewein C, Eckhardt I, Momma S, Figarella-Branger D, Fulda S. Smac mimetic promotes glioblastoma cancer stem-like cell differentiation by activating NF-kappaB. Cell Death Differ 2014; 21: 735-747.

27. Tchoghandjian A, Baeza-Kallee N, Beclin C, Metellus P, Colin C, Ducray F et al. Cortical and subventricular zone glioblastoma-derived stem-like cells display different molecular profiles and differential in vitro and in vivo properties. Ann Surg Oncol 2012; 19(Suppl 3): S608-S619.

28. Tchoghandjian A, Baeza N, Colin C, Cayre M, Metellus P, Beclin C et al. A2B5 cells from human glioblastoma have cancer stem cell properties. Brain Pathol 2010; 20: 211-221.

29. Denicolai E, Baeza-Kallee N, Tchoghandjian A, Carre M, Colin C, Jiglaire CJ et al. Proscillaridin $\mathrm{A}$ is cytotoxic for glioblastoma cell lines and controls tumor xenograft growth in vivo. Oncotarget 2014; 5: 10934-10948.

30. Heinicke U, Kupka J, Fichter I, Fulda S. Critical role of mitochondria-mediated apoptosis for JNJ-26481585-induced antitumor activity in rhabdomyosarcoma. Oncogene 2015; 35 : 3729-3741.

31. Nicoletti I, Migliorati G, Pagliacci MC, Grignani F, Riccardi C. A rapid and simple method for measuring thymocyte apoptosis by propidium iodide staining and flow cytometry. J Immunol Methods 1991; 139: 271-279.

32. Nguyen TH, Oberholzer J, Birraux J, Majno P, Morel P, Trono D. Highly efficient lentiviral vector-mediated transduction of nondividing, fully reimplantable primary hepatocytes. $\mathrm{Mol}$ Ther 2002; 6: 199-209.

33. Mathieu S, Prorok M, Benoliel AM, Uch R, Langlet $C$, Bongrand $P$ et al. Transgene expression of alpha(1,2)-fucosyltransferase-I (FUT1) in tumor cells selectively inhibits sialylLewis $x$ expression and binding to E-selectin without affecting synthesis of sialyl-Lewis a or binding to P-selectin. Am J Pathol 2004; 164: 371-383.

34. Erickson RI, Tarrant J, Cain G, Lewin-Koh SC, Dybdal N, Wong H et al. Toxicity profile of small-molecule IAP antagonist GDC-0152 is linked to TNF-alpha pharmacology. Toxicol Sci 2013; 131: 247-258.

35. Wong H, Budha NR, West K, Blackwood E, Ware JA, Yu R et al. Dogs are more sensitive to antagonists of inhibitor of apoptosis proteins than rats and humans: a translational toxicokinetic/toxicodynamic analysis. Toxicol Sci 2012; 130: 205-213.

36. Filonov GS, Piatkevich KD, Ting LM, Zhang J, Kim K, Verkhusha VV. Bright and stable nearinfrared fluorescent protein for in vivo imaging. Nat Biotechnol 2011; 29: 757-761.

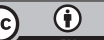

Cell Death and Disease is an open-access journal published by Nature Publishing Group. This work is licensed under a Creative Commons Attribution 4.0 International License. The images or other third party material in this article are included in the article's Creative Commons license, unless indicated otherwise in the credit line; if the material is not included under the Creative Commons license, users will need to obtain permission from the license holder to reproduce the material. To view a copy of this license, visit http://creativecommons.org/licenses/by/4.0/

(C) The Author(s) 2016

Supplementary Information accompanies this paper on Cell Death and Disease website (http://www.nature.com/cddis) 